\title{
PHP Programming for Achieving Students in Informatics Management Department State of Polytechnic Sriwijaya
}

\author{
Yusniarti $^{1, *}$ Henny Madora ${ }^{1}$ Ida Wahyunigrum ${ }^{1}$ Muhammad Noval ${ }^{1}$ \\ ${ }^{1}$ Informatics Management Department, Politeknik Negeri Sriwijaya. \\ *Corresponding author. Email: yusniarti1980@gmail.com
}

\begin{abstract}
This research aims to build an information system for achieving students at Management Informatics Department State of Polytechnic Sriwijaya for display useful information. Information System on this research is used to design systems using PHP programming. The application used in this research is to create a program using PHP programming. This system will be able to assist in the search for achieving students' data and their achievement arena. The result of this research will be implemented into a Web-based student information system in Management Department State of Polytechnic Sriwijaya.
\end{abstract}

Keywords: Information Systems, Internet

\section{INTRODUCTION}

State of Polytechnic Sriwijaya students has won various achievements in prestigious competitions at the Indonesian Polytechnic level, including the State of Polytechnic Sriwijaya who won the General Champion at the XII Student Sports and Arts Week (Porseni) 2018 with a total of 14 Gold, 18 silver and 11 bronze. The victory this time also succeeded in delivering the State of Polytechnic Sriwijaya to become the only contingent that won the overall title 3 times after the victories at Porseni IX in Palembang and Porseni X in Pontianak since the holding of the Porseni in 1999.

Also State of Polytechnic Sriwijaya also participates in the annual Student Achievement selection event which is an event for undergraduate and diploma students organized by the Ministry of Research, Technology and Higher Education. Every year, one person representing each department will meet in the Grand Final to compete for the Student Outstanding
Champion title and advance to the next round, namely the National Achievement Student Selection.

Behind the brilliant achievements, students who were selected and participate in the Student Achievement selection event have certainly gone through a long selection process which usually begins with a file selection process in their respective majors. However, the data collection itself was still done manually. It causes the data collection work for achieving students to be unstructured. It is not uncommon for a lot of data to be incomplete or missing because the data is not neatly arranged, because selection event for achieving students is only held once a year.

Therefore, State of Polytechnic Sriwijaya needs a computer application information system that can help to solve these problems. So, the author intends to make an application in the Management Department in the form of data processing information systems for the 
selection of achieving students in terms of registration, data collection of achieving students based on their branch of achievement, including name, identification numbers, etc. As well as an information system that can record information about the selection of achieving students including information on the requirements for selecting and documentation of achieving students. With this data processing application information system, it can simplify and accelerate the process of student registration and selection by the Department, as well as data collection by the Student Affairs section on achieving students through a more neatly structured data recap from the application without requiring a long time. The application is created using Web programming, which uses the PHP programming language with a database, namely MYSQL.

PHP is a language with opensource, where users can develop PHP function codes as needed. Students are people who study in tertiary institutions in other words. Achievement is the result of an activity that has been carried out, created either individually or in groups. Meanwhile, according to KBBI the word achievement has a meaning, namely, "achievement is the result that has been achieved (from what has been done, done, and so on)"

\section{STATEMENT OF PROBLEMS}

Based on the interviews and observations the researchers conducted, the researchers concluded the following problems:

1. Selection of registration files in the search of achieving students in the Information Management Department at State of Polytechnic Sriwijaya and data collection of achieving students is still not efficient.

2. There is no special application that can simplify the registration process, file selection and data collection of achieving students online and an application is needed that can inform about the activities of selecting achieving students majoring in informatics management at State of Polytechnic Sriwijaya.

\section{OBJECTIVE RESEARCH}

The objectives to be achieved from this research are as follows:

1. Creating an information system that can process registration and collection data online for achieving students majoring in informatics management in the selection of achieving students at State of Polytechnic Sriwijaya.

2. Providing information to campus, especially informatics management related to the selection of achieving students at State of Polytechnic Sriwijaya.

\section{RESEARCH BENEFITS}

The benefits of doing this research are as follows:

1. Management of the Student Achievement selection will be easier in processing data, especially registration file data in the selection event for achieving students majoring in informatics management at State of Polytechnic Sriwijaya.

2. With this application, it can help students in finding literature data for registration files and information on achieving students

\section{APPLICATION REVIEW}

\subsection{Previous Research}

Ratna Haryani M.M.W. Tairas in her research entitled Achievement motivation for achieving students from economically disadvantaged families, argued that in general, it provides criteria for achieving students, namely students who have successfully achieved high achievement, both academic and non-academic, are able to communicate in Indonesian and English, have an attitude positive, and has a Pancasila spirit (Depdiknas, 
2010). Specifically, the criteria for achieving students can be seen from the GPA, scientific writing, being active in curricular, co-curricular and extra-curricular activities, being able to speak English well, and having a good personality.

Meanwhile, research conducted by Melisa Kurnia Asfitri and Lukmawati Achievement motivation is a need that encourages individuals to achieve success or excellence by considering the standards that must be achieved both intrinsic and extrinsic in nature and aims to obtain success incentive values. Achievement motivation has a big role in the achievements of a person. Research shows that people who have high achievement motivation will have better performance when compared to people who have low achievement motivation.

\subsection{References Related to Research}

\subsubsection{Application program and data processing}

Definition of System

Pratama (2014: 7), "the system is defined as a collection of procedures that are interrelated and interconnected to carry out a task together. Broadly speaking, the system consists of three main components, namely hardware, software and brain ware.

Suryantara (2017: 1), "the system consists of components that are interconnected with one another and work together to achieve a goal.

Definition of Information

According to Sutarman (2012: 14) information is a collection of facts (data) that are organized in a certain way so that they have meaning for the recipient.

According to Hartono (2013: 15) Information is basically a set of data that has been processed into something that has broader meaning and use.

Definitions of Information System
According to Sutari (2012: 48) an information system is a system within an organization that brings together the needs of managing daily transactions that support managerial organizational functions with the strategic activities of an organization to be able to provide certain outsiders with the necessary reports.

According to Hutahahean (2014: 13) an information system is a system within an organization that brings together the needs of managing daily transactions, supports operations, is managerial in nature, and strategic activities of an organization and provides external parties with the required reports.

Definitions of Website

Website or also called web is a page displayed on the internet which contains certain (special) information. The web was first introduced in 1992. This was the result of a development effort by CERN in Switzerland. The internet and the web are two different things, the internet is what can display the web, while the web is what is displayed in the form of an arrangement of pages that use Web technology and are related to one another (Wahyudi, 2015: 13).

World Wide Web or Web is a subsystem of the internet. The World Wide Web is a very popular area where it provides all kinds of information from around the world and presents in multimedia (Sindharta, 1996: $1)$.

1. Definition of Hypertext Markup Language (HTML)

Hypertext Markup Language (HTML) is a system for adding documents with tables that indicate how the text in the document should be presented and how the documents are linked together. Within the HTML add-on scheme there is the power to create client-server applications, multimedia and interactive forms. HTML is actually an ASCII document or plain 
text designed not to depend on one particular operating system (Sulhan, 2006: 25).

2. Definition of Cascading Style Sheet (CSS) Cascading Style Sheet (CSS) is a web programming language to control several components in a web so that it will be more structured and uniform. Similarly, styles in word processing applications such as Microsoft Word can set several styles, such as headings, sub-chapters, body text, footers, images, and other styles to be used together in several files. In general, CSS is used to format the appearance of web pages created in HTML and XHTML languages.

CSS can control Image size, body color on text, table color, border size, hyperlink color, mouse over color, space between paragraphs, spacing between text, left, right, top, bottom margin, and other parameters. CSS is a style sheet language used to adjust the appearance of documents. With the CSS it allows us to display the same page with different formats (Wahyudi, 2015: 16).

\section{Definition of MYSQL}

MYSQL or read as 'MY sequel' is a letter of RDBMS (relational database management system), which is a system application that describes data processing functions (Sibero, 2015: 97).

4. Definition of PHP (PHP hypertext preprocessor)

PHP is a language with open copyright or also known as opensource, where users can develop PHP function codes as needed. (sibero, 2014: 49)
5. Definition of Progressive Web Application (PWA)

Progressive Web Application An amalgamation of web apps and mobile apps. Previously, Mobile Apps were JavaScript applications that ran on the browser and aimed to bring native app features to the website. With the introduction of new web APIs, PWAs can help bring the UI and UX of applications to the web browser on your mobile device. So, Progressive Web Apps are traditional web applications that are enhanced with modern web technologies, enabling them to provide a more app-like experience. (www.dewaweb.com).

6. Definition of Program Flowchart (Flowchart) Flowcharts are a way of visual presentation of data flow through information systems, flowcharts can help explain the work currently being done and how to improve or develop that work.

\section{RESEARCH METHODES}

\subsection{Time and place}

This research was conducted for eight (8) months with a case study of information system students who excel in the management of informatics at the State of Polytechnic Sriwijaya of Palembang, having their address at Jl. Srijaya The big hill country of Palembang.

\subsection{Stages in research}

In the initial investigation stage, the writer observes what is needed and expected from this application system. Therefore, the authors build an application about the web-based outstanding student information system with the following conditions: 
1. This information system has a web site display that has features and menus, this menu will contain data for data search for achieving students from registration to branch of achievement.

2. With this data processing application, it can simplify and accelerate the student registration process and selection by the Department, as well as data collection by the Student Affairs section on achieving students through a more neatly arranged data recap from the application without requiring a long time. The application is created using Web programming, which uses the PHP programming language with a database, namely MYSQL.

3. The information system on this website also includes a search for outstanding student data, as well as an application that can record information about the selection of achieving students including information on the requirements for selecting achieving students and documentation of student achievement selection activities.

4. This information system can facilitate the data processing of achieving students majoring in Information Management, State of Polytechnic Sriwijaya

\section{TOOLS AND MATERIALS}

\subsection{Tools}

The tools used to build an web-based information system for achieving students in the Management Informatics Department at the State of Polytechnic Sriwijaya are as follows:

\section{a. Hardware}

The hardware used is a laptop and printer with the following specifications:
1. Intel $\AA^{\circledR}$ Core $^{\mathrm{TM}} \mathrm{i7}$

2. Installed 4.00 GB RAM memory

3. System type 64-bit Operating System, x64based processor

4. Canon iP2700 printer

5. 32 GB Toshiba Flash Disk

b. Software

Software details as follows :

1. Microsoft Windows 10, as the operating system of the laptop used.

2. PHPMyAdmin, is used to design the database of the application to be made.

3. XAMPP v3.2.3, is a combination of a local server, PHP (Hyper Prepocessor) as a script, and MySQL as the database.

4. Sublime Text 3, coding is used in making applications

5. Microsoft Visio Standard 2007, is used to design the system design diagram display.

\subsection{Materials}

The author uses several materials in the form of data in this study including:

1. Information about the list of data on achieving students in the Department of Information Management, State of Polytechnic Sriwijaya.

2. Information about achievement branch data held in the Department of Information Management, State of Polytechnic Sriwijaya.

3. Service development at this stage, the design is carried out starting from making a flowchart system to build an information system 
application. Flowchart is a depiction of the flow of the web-based Information System application of achieving students in the Department of Information Management, State of Polytechnic Sriwijaya.

4. Application Integration, at this stage designing the website of achieving students majoring in Department of Information Management, State of Polytechnic Sriwijaya.

5. Testing the system, at this stage after the manufacturing process is complete and the system can run, the testing phase can be started.

\subsection{System Development Method}

This system development method will be carried out by referring to the Agile SDLC adaptation system development model as follows:

1. Data analysis and problem formulation.

This stage is the initial stage of research, where data collection begins both data on achieving students and data generated from field observations.

\section{Defining}

At this stage, the necessary data is collected to create a website application in the department of informatics management on systems created in the system development research process.

\section{Service Development}

At this stage, the design is carried out starting from making a flowchart system to program flowchart in order to build an information system application for achieving students in the Department of Information Management, State of Polytechnic Sriwijaya. Flowchart is a depiction of the flow of the Information System application for achieving students of the Department of Information Management, State of Polytechnic Sriwijaya. Flowchart consists of student admin flowchart, department admin flowchart, student flowchart (user).

\section{Application Integration}

At this stage, the design of the outstanding student website at Department of Information Management, State of Polytechnic Sriwijaya.

\section{System testing}

At this stage, after the manufacturing process is complete and the system can run, the testing phase can be started and focused on the software to ensure that all parts have been tested. This is done to minimize errors and ensure the resulting output is as desired.
6. System implementation and system maintenance

At this stage it is carried out to test the feasibility level of the system from the website and at this stage the web also needs to be maintained, maintenance aims so that the system that has been implemented can follow developments and changes to the web that has been implemented

\section{APPLICATION VIEW}

a. Display Student Registration Page

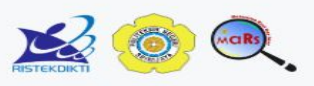

Nim

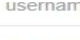

Password

n...n.

Daftar 
b. Display the student login page

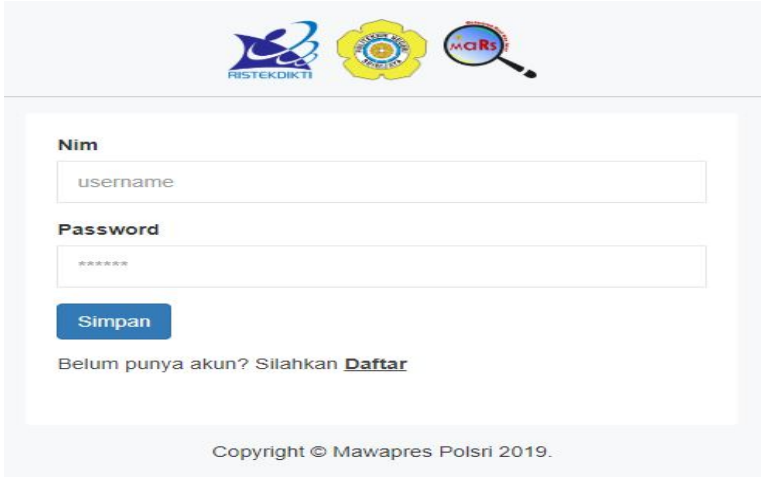

C. Display of student login homepage 중

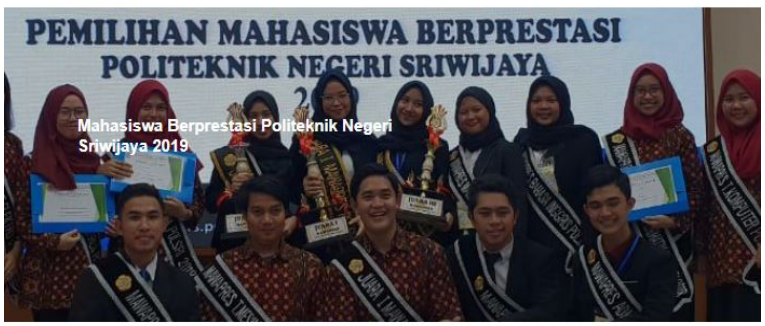

Alur Pendaftaran Mawapres Polsri

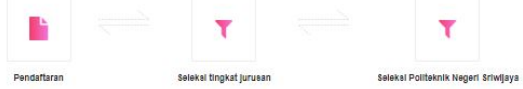

d. Display of Student Achievement Data page
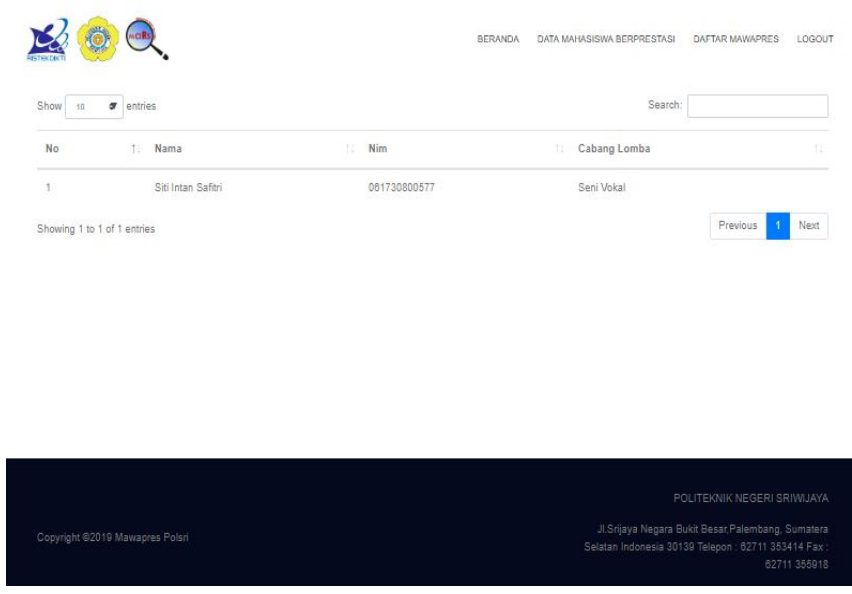

e. Display of Student Achievement Registration page
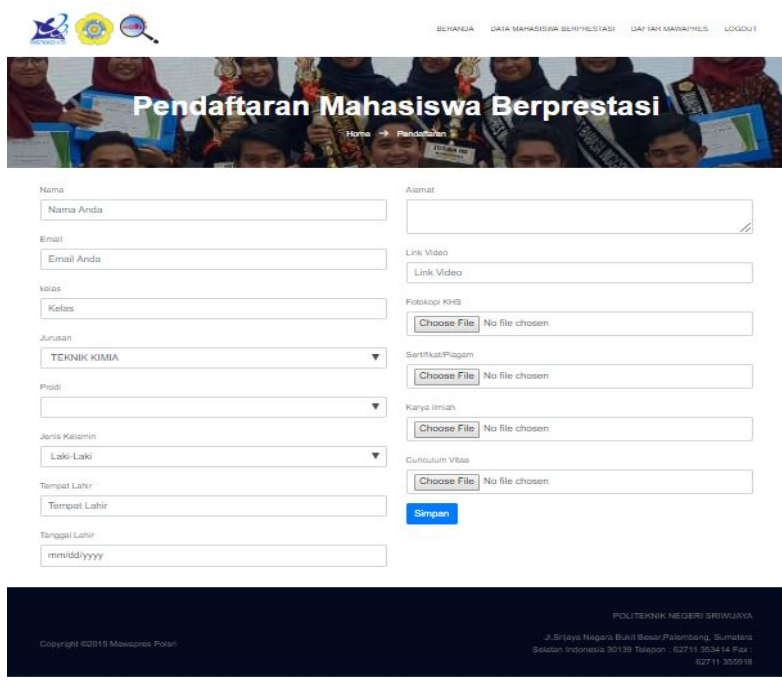

f. Display of the Competition Branch Entry Page

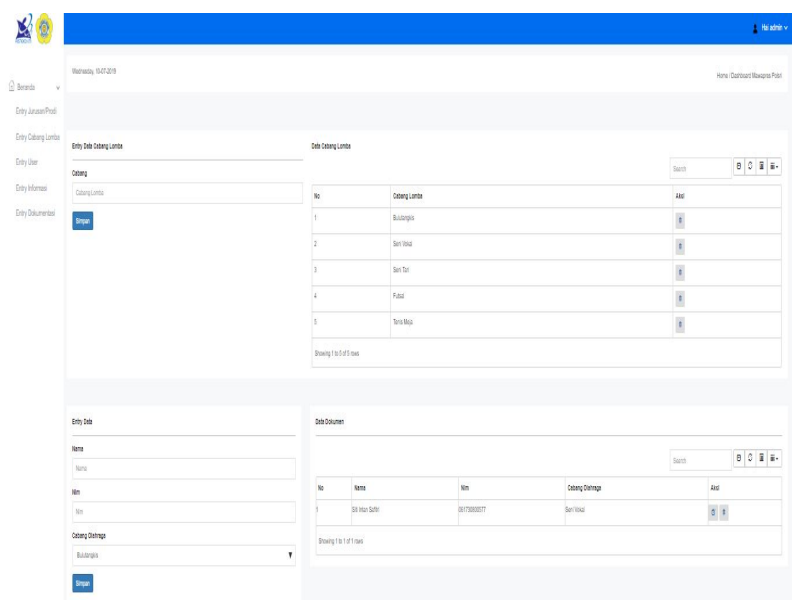

g. User Entry Page Display

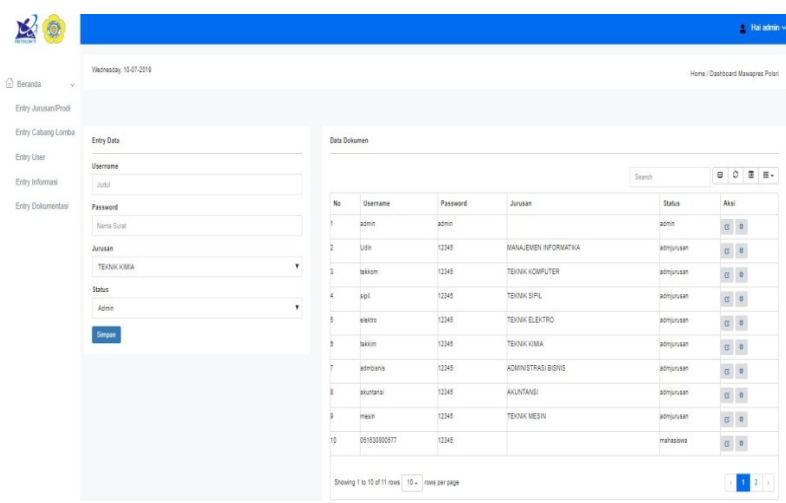


h. Display Information Entry Page

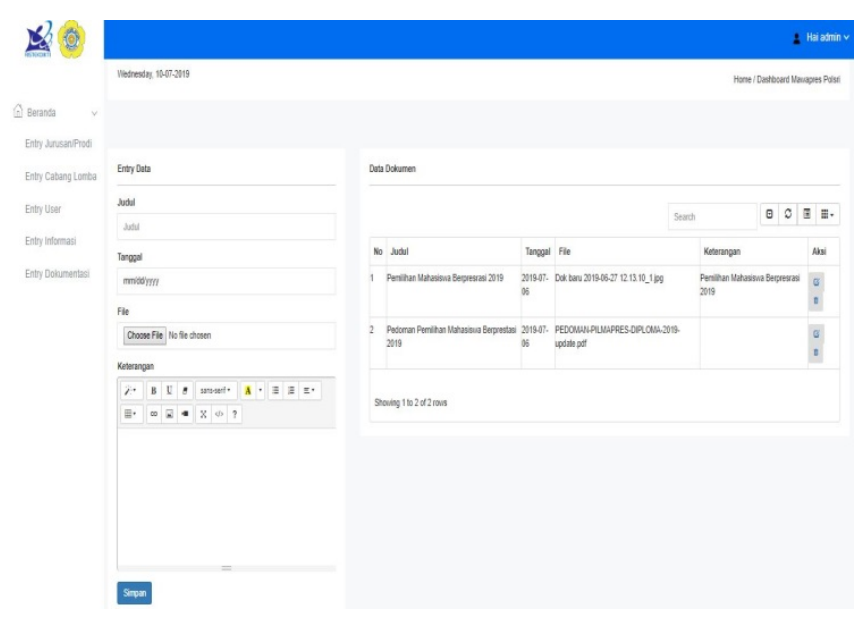

2. This system has a student registration page, login page, student data page with achievement, home page, competition branch page, user entry, information entry and reports.

\subsection{Suggestion}

This information system was created to be implemented and help the performance of the student affairs department staff in inputting outstanding student data, and kind of competitions were contested by the Department of Information Management, State of Polytechnic Sriwijaya.

\section{REFERENCES}

i. Report Page Views

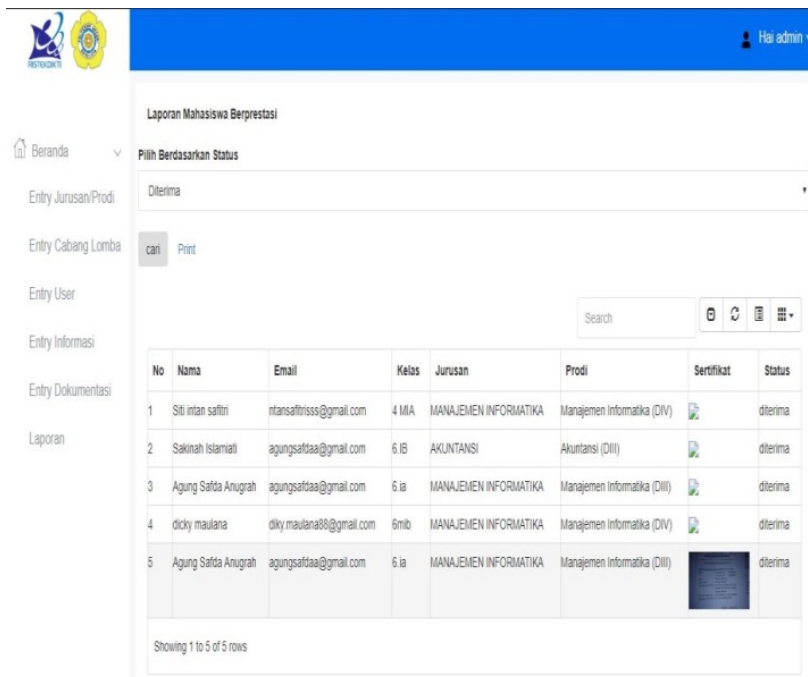

\section{CONCLUSION AND SUGGESTIONS}

\subsection{Conclusion}

Based on the discussion that has been stated in the previous chapters, in general, it can be concluded that several things are as follows:

1. This Information system can process the information and data collection of Achieving students majoring in Department of Information Management, State of Polytechnic Sriwijaya.
[1] Budiutomo, Nanang. 2017.Flowchart Symbols and Their Functions.https://bukubiruku. com/symbolflowchart-and-its-functions/. (Retrieved February 26, 2019)

[2] Febrian, Jack. 2007. Dictionary of Computer Information Technologi \& Telecommunications.Bandung: Informatics

[3] Gani, Lutfi. 2018. Practical GuideMenguasai Vue.js. Yogyakarta: Lokomedia

[4] Hadi, AgusPrawoto. 2018. AlloysCompleteMah JSON. https://jagoweb.com/memahami-json/. (Retrieved February 26, 2019)

[5] Cooperation between Andi Publisher and Wahana Komputer. 2012. Most Wanted! Java Script Source Code. Yogyakarta: Andi Offset

[6] Kristanto, Harianto. 2004. Database Concept and Design. Andi.

[7] Nathasya, what's going on? 2018. Progressive Web Apps To Make Websites Faster \& Engaging. https://www.dewaweb.com/blog/progressive-webapps/. (Retrieved March 4, 2019)

[8] Sibero,Alexander F.K.2014.web Programming power pack.yogyakarta: MediaKom.

[9] Sindharta, Lani. 1996. Free Internet Information. Jakarta: Elex Media Komputindo

[10] Sulhan, Moh. 2006. Web-based Application Development with PHP and ASP. Malang: Gava Media 